\title{
Rooftop photovoltaics potential assessment: A framework to integrate technological, economic, environmental and social benefit
}

\author{
Yu Ping ${ }^{1}$, Zhu Yifan ${ }^{1}$ and Wang Peng ${ }^{1, *}$ \\ ${ }^{1}$ Faculty of Civil Engineering and Mechanics, Jiangsu University, Jiangsu, China
}

\begin{abstract}
Buildings have a significant impact on global and local energy demand and climate change. Consequently, the issue of photovoltaic (PV) potential assessment of building roofs have been extensively studied. Although studies have adopted different methods to predict the various potentials of rooftop PVs, as yet there is no understanding of a comprehensive framework for evaluating the potential of rooftop PVs. This study aims to develop a new framework to evaluate the technical, economic, environmental, and social benefits of rooftop PVs in old communities in Nanjing. The study found that the total annual electricity generation of rooftop PVs in the two districts of Nanjing was 431,136,314 KWh, which can meet about $20 \%$ of the residential electricity demand in the study area; the total electricity generation in the life cycle of 25 years was $5327909814 \mathrm{KWh}$; The economic benefit was 4.06 yuan/wp; the $\mathrm{CO} 2$ emission efficiency was $20.02 \%$; the social benefit was 11.224 yuan/KWh. The results of this study will potential provide valuable reference suggestions for urban planners from the perspective of the benefits brought by rooftop PV in the two districts.
\end{abstract}

\section{Introduction}

With the intensification of climate change and air pollution, many countries had adopted different response measures to reduce pollutant emissions and mitigate climate change [1]. In this process, the renewal and transformation of the city was particularly important. Improving the energy performance of existing old buildings had a great potential to reduce carbon dioxide emissions at a relatively low cost [2]. Renovating the building envelope to reduce the energy demand and carbon emissions of existing old buildings was the most common method in the urban renewal process [3], but these are not enough. Rooftop PV is an effective way of energy saving and emission reduction, which has been known by the public. As an important part of building energy saving and emission reduction, the potential assessment of rooftop PV affects energy planning and the feasibility of installing PVs. Therefore, only by accurately predicting the potential of rooftop PV capacity can the actual value of rooftop PV applications in the buildings be effectively analyzed. In addition, the rooftop PV electricity generation potential prediction, as the basis for solar planning and PV construction, can also help solve the energy crisis and improve energy efficiency. In order to promote the application of rooftop PVs in the residential buildings, it is crucial to quantify the potential of rooftop PVs. In recent years, there has been a lot of research on the evaluation of rooftop PV potential. For example, Peng and $\mathrm{Lu}$ [4] evaluated the development potential of rooftop PVs from two aspects of energy and environmental benefits; Gagnon et al. [5] used GIS methods to evaluate the technical potential of rooftop PVs; Jo and Otanicar [6] used a hierarchical approach to assess the capacity potential and indirect benefits of rooftop PVs. It can be seen that previous researches mainly focused on using different methods to evaluate rooftop PVs from one or two aspects, but a new comprehensive evaluation framework has not been established to fully analyze the practical application potential of rooftop PVs. The studied area of Qinhuai and Gulou Districts are located in Nanjing City, and has a total building roof area of $4.15 \mathrm{~km}^{2}$. With an average annual total solar radiation of $5215.52 \mathrm{MJ} / \mathrm{M}^{2}$ per year, they are the districts with the largest usable roof area in the central area of Nanjing. Furthermore, total social electricity consumption in the two districts has undergone increase in last 30 years, and the electricity consumption in 2018 was about four times that of 1988. This trends are expected to continue to grow in the future, indicating the serious threats to the study area's energy security. In this context, installing rooftop PV is an effective option to solve the energy crisis. This study summarized previous studies, developed a framework for comprehensive assessment of rooftop PV potential. We used GIS-based method and BIGEMAP data to calculate the roof PV electricity generation potential of the old

\footnotetext{
* Corresponding author: upeswp@ujs.edu.cn
} 
communities in Qinhuai and Gulou Districts of Nanjing City, then analyzed the economic, environmental and social benefits to provide energy planners some certain basic suggestions.

\section{Data and methods}

\subsection{Data sources}

The electricity consumption data of Qinhuai and Gulou Districts for 2017 in this study was from the "Nanjing Statistical Yearbook"; then the GDP and annual total electricity production data were from "China Statistical Yearbook"; finally, the annual total solar radiation data was calculated from the European Centre for MediumRange Weather Forecasts (ECMWF).

\subsection{Methods}

\subsubsection{Calculation of rooftop PV electricity generation}

The calculation of roof PV electricity generation mainly included four steps, which were referred from [7][8][9]. As can be seen from the Figure 1, the first step was to calculate the optimal inclination angle $(\beta)$ and spacing between the PV panels $(d)$ through the local latitude $(\phi)$ and the length of the PV panels $(L)$. The second step was to select 12 noon on the summer solstice to calculate the solar radiation under the optimal inclination angle $\left(H_{T}\right)$. First, calculated the declination angle $(\delta)$ and time angle $(\omega)$; then calculated the solar altitude angle $(\sinh )$, solar constant $\left(I_{0}\right)$, atmospheric mass $(m)$, and atmospheric transparency coefficient $(P)$; according to the total solar radiation $(H)$, the direct radiation $\left(H_{b}\right)$ and scattered radiation $\left(H_{d}\right)$ of the sun were calculated (without considering the reflected radiation), and finally the solar radiation at the optimal tilt angle of the PV panel $\left(H_{T}\right)$ was calculated. The third step was to locate and filter the 734 old communities in the study area by importing the building outline vector file in BIGEMAP into the GIS software, remove the area affected by the elevator shaft and its shadow in the roof, the area affected by the shadow of the parapet wall of the flat roof, and the area of the back sun surface of the sloping roof, to obtain the total usable area of the roof of the old community. The fourth step was to calculate the total roof PV panel laying area based on the number of solar panels per unit area, the total available roof area and the area of a single PV panel. Finally, the roof PV electricity generation was calculated as follows,

$$
E_{p v}=\eta * A_{p v} * H_{T} * P R *\left(1-F_{s}\right)
$$

Which $E_{p v}$ is the total electricity generation of rooftop PV; $\eta$ is the efficiency of rooftop PV modules; $P R$ is the performance ratio; $F_{S}$ is the shading coefficient; in this study, $\eta=15 \%, P R=0.8, F_{S}=0.05$.

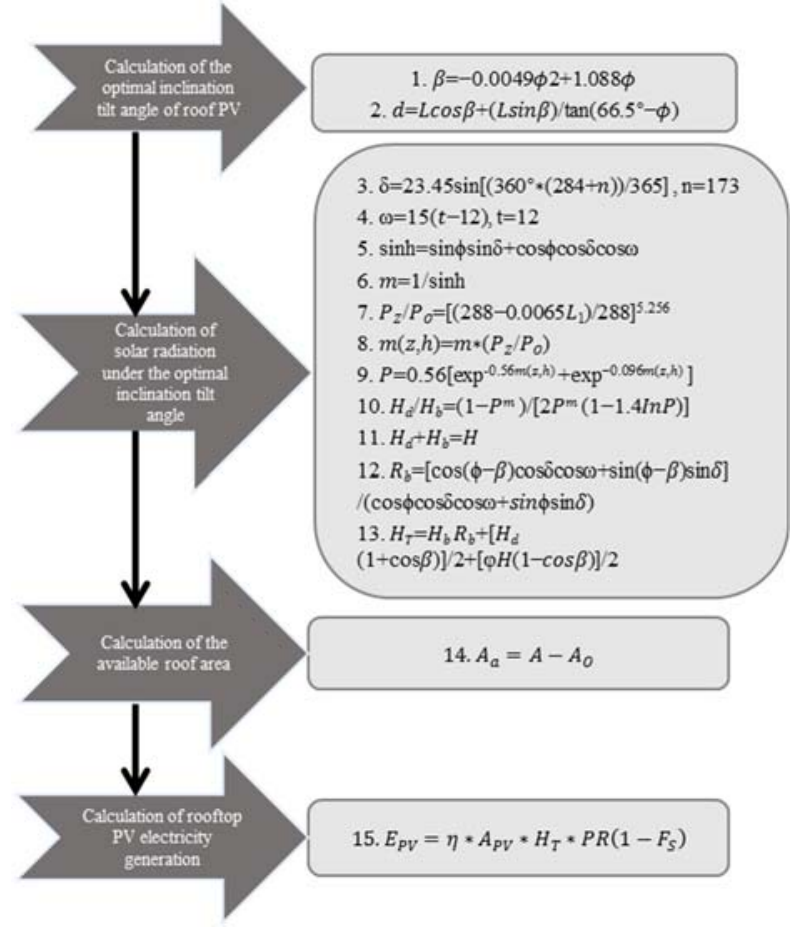

Fig. 1. Calculation flow chart of rooftop PV electricity generation

\subsubsection{Calculation of economic benefits of rooftop PV}

This study referred to the method in [10] to calculate the economic benefits of rooftop PV in old communities. First, calculated the life cycle electricity generation capacity of the rooftop PV. Assuming that the service life of PV panel was 25 years, the specifications of PV modules were shown in Table 1 . The electricity generation efficiency of PV panel is $85 \%$, and the conversion efficiency of inverters is $98.70 \%$. The power attenuation rate of the module referred to the data in [11]. Then calculated the life cycle maintenance cost of roof PV, the daily maintenance cost is 8 yuan/(kw.year) [10], and finally calculated the economic benefit of roof PV according to the following formula.

The economic benefit of roof $P V=(P V$ electricity generation revenue-total daily maintenance costs) / installed capacity

$P V$ electricity generation revenue $=$ total electricity generation throughout the life cycle $\times$ residential electricity price

Total daily maintenance cost $=$ total installed capacity $\times 8 \times 25$

(4)

Table 1. Specifications of PV modules.

\begin{tabular}{|c|c|c|}
\hline $\begin{array}{c}\text { Standard } \\
\text { battery pack } \\
\text { size }\end{array}$ & $\begin{array}{c}\text { Component } \\
\text { power } \\
(\mathrm{wp})\end{array}$ & $\begin{array}{c}\text { Installed power } \\
\text { per square meter } \\
(\mathrm{wp})\end{array}$ \\
\hline $\begin{array}{c}1650 \times \\
990 \mathrm{~mm}^{2}\end{array}$ & 260 & 159.17 \\
\hline
\end{tabular}
2.2 .3 Calculation of environmental benefits of
rooftop PV 
The environmental benefits in this study mainly referred to the $\mathrm{CO} 2$ emission efficiency. First, calculated the $\mathrm{CO} 2$ emission reduction based on the PV electricity generation on the roof of the old community, and then calculated the total carbon emission of the residents' daily electricity consumption by the residents' annual electricity consumption. Finally, the ratio of the two was the carbon emission efficiency of the rooftop PV of the old community.

\subsubsection{Calculation of social benefits of rooftop PV}

According to [12], the social benefits of rooftop PV were composed of the national economic value of electricity and the environmental value of rooftop PV. The formula for calculating the social benefits of rooftop PVs $\left(b_{s}\right)$ was as follows:

$$
b_{s}=p_{s}+b_{E}
$$

\section{$p_{s}=G D P /$ National annual total electricity generation}

$b_{E}=$ Total emission reduction of pollutant/Total environmental benefits from emission reduction

Which $\mathrm{p}_{\mathrm{s}}$ is the national economic value of electricity, expressed in the shadow price of the national economy of electricity; $b_{\mathrm{E}}$ is the environmental benefit of rooftop PV; China's average coal consumption for power supply in 2017 was $308 \mathrm{~g} / \mathrm{KWh}$ [12]. Table 2 shows the pollutant gases emitted by the combustion of $1 \mathrm{t}$ standard coal and the environmental costs per unit of emissions. Then the pollutant emission reduction and environmental benefits of the rooftop PV throughout the life cycle were calculated, and finally the social benefits of rooftop PV were obtained.

Table 2. Unit pollutant emission reduction coefficient and environmental cost

\begin{tabular}{|c|c|c|}
\hline Pollutants & $\begin{array}{c}\text { Pollutant } \\
\text { emission factor } \\
(\mathrm{kg} / \mathrm{t})\end{array}$ & $\begin{array}{c}\text { Environmental } \\
\text { cost (yuan/kg) }\end{array}$ \\
\hline $\mathbf{C O}_{2}$ & 26621 & 0.023 \\
\hline $\mathbf{S O}_{2}$ & 22 & 6 \\
\hline $\mathbf{N O}_{\mathbf{x}}$ & 10 & 8 \\
\hline TSP & 17 & 2.2 \\
\hline
\end{tabular}

\section{Results}

Figure 1 presents the total available roof area and annual total electricity generation of rooftop PV in Gulou and Qinhuai of the old community. The available roof area of the old community in Gulou was $2.22 \mathrm{~km}^{2}$, and the total annual electricity generation of rooftop PV was $230186630.3 \mathrm{KWh}$; the available roof area of the old community in Qinhuai was $1.93 \mathrm{~km}^{2}$, and the total annual electricity generation was $200949683.7 \mathrm{KWh}$.

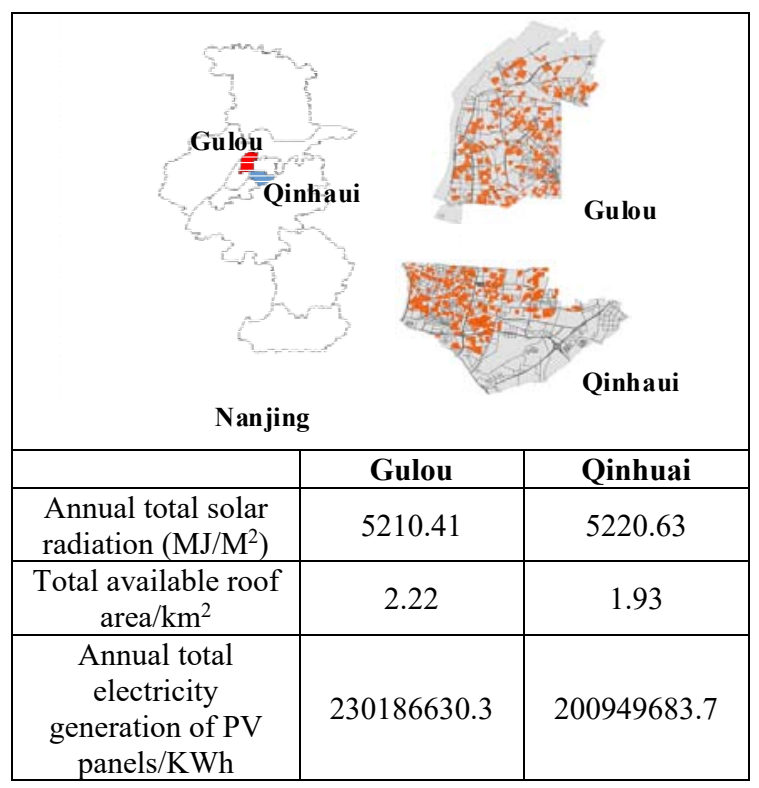

Fig. 2. Rooftop photovoltaic electricity generation potential

Table 3 shows the forecast results of electricity generation during the 25-year life cycle of rooftop PV. The results showed that the estimated electricity generation of rooftop PV in 25 years was $5327909814 \mathrm{KWh}$. Therefore, the electricity generation income of rooftop PV was 2814734755 yuan; the total daily maintenance cost of rooftop PVs was 132286148.9 yuan, and then it can be calculated that the economic benefit per watt of rooftop PV was 4.06 yuan/wp.

Table 3. Rooftop PV electricity generation forecast for the life cycle

\begin{tabular}{|c|c|c|}
\hline Time/year & $\eta \mathrm{N} / \%$ & $\begin{array}{c}\text { Annual electricity } \\
\text { generation } \\
\text { capacity/KWh }\end{array}$ \\
\hline 1 & $100 \%$ & 431136314 \\
\hline 2 & $97.50 \%$ & 420357906.2 \\
\hline 3 & $96.80 \%$ & 406906453.2 \\
\hline 4 & $96.10 \%$ & 391037101.5 \\
\hline 5 & $95.40 \%$ & 373049394.8 \\
\hline 6 & $94.70 \%$ & 353277776.9 \\
\hline 7 & $94.00 \%$ & 332081110.3 \\
\hline 8 & $93.30 \%$ & 309831675.9 \\
\hline 9 & $92.60 \%$ & 286904131.9 \\
\hline 10 & $91.90 \%$ & 263664897.2 \\
\hline 11 & $91.20 \%$ & 240462386.2 \\
\hline 12 & $90.50 \%$ & 217618459.5 \\
\hline 13 & $89.80 \%$ & 195421376.7 \\
\hline 14 & $89.10 \%$ & 174120446.6 \\
\hline 15 & $88.40 \%$ & 153922474.8 \\
\hline 16 & $87.70 \%$ & 134990010.4 \\
\hline 17 & $87.00 \%$ & 117441309.1 \\
\hline 18 & $86.30 \%$ & 101351849.7 \\
\hline 19 & $85.60 \%$ & 86757183.35 \\
\hline 20 & $84.90 \%$ & 73656848.67 \\
\hline 21 & $84.20 \%$ & 62019066.58 \\
\hline 22 & $92.60 \%$ & 57429655.65 \\
\hline 23 & $91.90 \%$ & 52777853.54 \\
\hline 24 & $91.20 \%$ & 48133402.43 \\
\hline 25 & $90.50 \%$ & 43560729.2 \\
\hline
\end{tabular}




\begin{tabular}{|c|c|}
\hline $\begin{array}{c}\text { Total electricity } \\
\text { generation/KWh }\end{array}$ & 5327909814 \\
\hline
\end{tabular}

Table 4 provides the calculation results of the carbon emission efficiency of rooftop PV. As can be seen from the table, the total life cycle emission reduction of Gulou and Qinhuai rooftop PV can reached $3535002183 \mathrm{~kg}$, and the carbon emissions generated by residential electricity consumption was $17,656127470 \mathrm{~kg}$. Therefore, the carbon emission reduction efficiency of rooftop PV was $20.02 \%$.

Table 4. Rooftop PV carbon emission efficiency

\begin{tabular}{|c|c|c|c|}
\hline District & $\begin{array}{c}\text { Annual } \\
\text { electricity } \\
\text { generation } \\
\text { capacity/KWh }\end{array}$ & $\begin{array}{c}\mathrm{CO} 2 \\
\text { emission } \\
\text { reduction/kg }\end{array}$ & $\begin{array}{c}\text { Carbon } \\
\text { emission } \\
\text { efficiency }\end{array}$ \\
\hline Gulou & 230186630.3 & 1887361872 & \multirow{7}{*}{$20.02 \%$} \\
\hline Qinhuai & 200949683.7 & 1647640311 & \\
\hline \multicolumn{2}{|r|}{ Total } & 3535002183 & \\
\hline District & $\begin{array}{l}\text { Total annual } \\
\text { electricity } \\
\text { consumption } \\
/ \text { KWh }\end{array}$ & $\begin{array}{c}\mathrm{CO2} \\
\text { emission } \\
\text { reduction/kg }\end{array}$ & \\
\hline Gulou & 1232468081 & 10105336098 & \\
\hline Qinhuai & 920910424.1 & 7550791371 & \\
\hline \multicolumn{2}{|c|}{ Total } & 17656127470 & \\
\hline
\end{tabular}

The calculation results of the national economic value of electricity and the environmental value of rooftop PV are plotted in Table 5 and Table 6 . The average economic value of electricity in China had increased from 9.40 yuan/KWh in 2009 to 12.73 yuan/ KWh in 2017 (Table 5). Then the 9-year average value of 10.96 yuan/KWh was used as the average economic value of the current rooftop PV.

Table 5. Average value of electricity in China

\begin{tabular}{|c|c|c|c|c|}
\hline \multirow{10}{*}{$\mathrm{p}_{\mathrm{s}}$} & years & $\begin{array}{c}\text { GDP/100 } \\
\text { million } \\
\text { yuan }\end{array}$ & $\begin{array}{c}\text { Electricity } \\
\text { production/10 } \\
0 \text { million } \\
\text { KWh }\end{array}$ & $\begin{array}{c}\text { Average } \\
\text { value of } \\
\text { electricity in } \\
\text { China } \\
\text { (yuan/KW } \\
\text { h) }\end{array}$ \\
\hline & 2009 & 349081.4 & 37146.5 & 9.40 \\
\hline & 2010 & 413030.3 & 42072 & 9.82 \\
\hline & 2011 & 489300.6 & 47130.2 & 10.38 \\
\hline & 2012 & 540367.4 & 49875.5 & 10.83 \\
\hline & 2013 & 595244.4 & 54316.4 & 10.96 \\
\hline & 2014 & 643974 & 56495.8 & 11.40 \\
\hline & 2015 & 689052.1 & 58145.7 & 11.85 \\
\hline & 2016 & 743585.5 & 61425 & 12.11 \\
\hline & 2017 & 827121.1 & 64951 & 12.73 \\
\hline
\end{tabular}

The total emissions of pollutants were 43765369.26 tons, of which $\mathrm{CO}_{2}$ emissions were the largest, 43684960.45 tons, $\mathrm{SO}_{2}$ emissions were 36101.92 tons, $\mathrm{NO}_{\mathrm{X}}$ emissions were 16409.96 tons, and TSP emissions were 27896.94 tons. The total environmental benefit of rooftop PV emission reduction was 1414018548 yuan (Table 6). Therefore, the environmental value of rooftop photovoltaic was 0.265 yuan/KWh. Finally, we calculated the social benefit of rooftop photovoltaic as 11.224 yuan/KWh.

Table 6. Pollutant emission reduction and environmental benefits

\begin{tabular}{|c|c|c|}
\hline Pollutants & $\begin{array}{c}\text { Emission } \\
\text { reduction /kg }\end{array}$ & $\begin{array}{c}\text { Environmental } \\
\text { benefits/yuan }\end{array}$ \\
\hline $\mathrm{CO} 2$ & 43684960447 & 1004754090 \\
\hline $\mathrm{SO} 2$ & 36101916.9 & 216611501.4 \\
\hline NOX & 16409962.23 & 131279697.8 \\
\hline TSP & 27896935.79 & 61373258.73 \\
\hline Total & 43765369262 & 1414018548 \\
\hline
\end{tabular}

\section{Conclusions}

In this paper, we calculated the electricity generation potential of rooftop PV in the old communities in Gulou and Qinhuai Districts, Nanjing. On this basis, we analyzed the economic, environmental and social benefits of roof PV in old communities. The study found that the total roof PV electricity generation of the old communities in Gulou and Qinhuai Districts was $431136314 \mathrm{KWh}$, which can meet $20 \%$ of the residential electricity demand of the two districts; The economic benefit per watt of rooftop photovoltaic was 4.06 yuan/wp. And the carbon emission reduction efficiency of rooftop PV was $20.02 \%$, the social benefit was 11.224 yuan/KWh. The results can provide suggestions for the energy planning and environmental governance of Qinhuai and Gulou Districts in Nanjing City.

\section{References}

1. (IEA), I.E.A. World Energy Outlook; Paris: IEA, 2013;

2. Ürge-Vorsatz, D.; Harvey, L.D.D.; Mirasgedis, S.; Levine, M.D. Mitigating CO2 emissions from energy use in the world's buildings. Build. Res. Inf. 2007, 35, 379-398, doi:10.1080/09613210701325883.

3. Aguacil, S.; Lufkin, S.; Rey, E. Active surfaces selection method for building-integrated photovoltaics (BIPV) in renovation projects based on self-consumption and self-sufficienc. Energy Build. 2019, 193, 15-28, doi:https://doi.org/10.1016/j.enbuild.2019.03.035.

4. Peng, J.; Lu, L. Investigation on the development potential of rooftop PV system in Hong Kong and its environmental benefits. Renew. Sustain. Energy Rev. 2013, 27, 149-162, doi:10.1016/j.rser.2013.06.030.

5. Gagnon, P.; Margolis, R.; Melius, J.; Phillips, C.; Elmore, R. Estimating rooftop solar technical potential across the US using a combination of GISbased methods, lidar data, and statistical modeling. Environ. Res. Lett. 2018, 13, doi:10.1088/17489326/aaa554.

6. Jo, J.H.; Otanicar, T.P. A hierarchical methodology for the mesoscale assessment of building integrated roof solar energy systems. Renew. Energy 2011, 36, 2992-3000, doi:10.1016/j.renene.2011.03.038.

7. Martín-Chivelet, N. Photovoltaic potential and land- 
use estimation methodology. Energy 2016, 94, 233242, doi:10.1016/j.energy.2015.10.108.

8. Jing, Y.; Meng, L.I.U.Z. Resources calculation of solar radiation based on matlab. New energy Technol. 2011, 01 , 35-38, doi:10.16189/j.cnki.nygc.2011.01.010.

9. Dandan, Z.; Da, Y. Calculation of Solar Radiation and Generated Energy on Inclined Plane and Optimal Inclined Angle. Build. Sci. 2012, 28, 4-8, doi:10.13614/j.cnki.11-1962/tu.2012.s2.063.

10. Taixiang, Z.; Hua, L.; Jiangtian, L.; Xun, M.; Junchuan, Y.; Mingmiang, J.; Zuming, L.; Liwei, D.; Qihao, S. Analysis of benefits and environmental benefits of different BIPV. J. Yunnan Norm. Univ.
2017, 37, 10-13, doi:DOI： 10.7699/j.ynnu.ns -2017017.

11. Chun, L.I.U.; Lei, S.; Peikang, W.; Xiaoping, G.A.O.; Corporation, E.; Shanghai, E.C. Application of Distributed Photovoltaic Power Generation in Shipyard Steel Structure Workshop. Electr. Energy Manag. Technol. 2016, 10, 66-71, doi:10.16628/ j.cnki.2095-8188.2016.10.014.

12. Xiliang, Z.; Jing, W. Social cost-benefit analysis and policy assessment for grid-connected solar photovoltaics system development in Western part of China. ACTA ENERGIAE SOLARIS Sin. 2007, 28, 32-36, doi:10.1017/CBO9781107415324.004. 